\title{
MECHANISM AND KINETICS FOR THE REACTION OF \\ FULMINIC ACID, HCNO, WITH AN AMINO RADICAL, $\mathrm{NH}_{2}$
}

\author{
Hue Minh Thi Nguyen, ${ }^{*}$ Trong Nghia Nguyen, ${ }^{2}$ Luc Vereecken ${ }^{3}$ \\ ${ }^{1}$ Faculty of Chemistry and Center for Computational Science, Hanoi National University of Education, Hanoi, \\ Vietnam \\ ${ }^{2}$ School of Chemical Engineering - Hanoi University of Science and Technology, Hanoi, Vietnam \\ ${ }^{3}$ Institute for Energy and Climate Research: IEK-8 Troposphere, Forschungszentrum Jülich GmbH, Jülich, Germany \\ * Corresponding author; email address: hue.nguyen@hnue.edu.vn; Telephone number: +84-944566456
}

Keywords: Reaction mechanism, $\mathrm{NH}_{2}$ radical, fulminic acid $\mathrm{HCNO}$, potential energy surface, RRKM Master equation

\begin{abstract}
The reaction of fulminic acid, $\mathrm{HCNO}$, with $\mathrm{NH}_{2}$ radicals was studied using quantum chemical and theoretical kinetic methodologies. B3LYP/6-311++G(3df,2p) calculations combined with $\operatorname{CCSD}(\mathrm{T})$ energy calculations at the basis set limit reveal a complex potential energy surface, where only two entrance channels contribute significantly to the product formation. Transition state theory and RRKM master equation calculations find a rate coefficient ranging from $7.2 \times$ $10^{-12} \mathrm{~cm}^{3}$ molecule $\mathrm{s}^{-1}$ at room temperature, to $>1 \times 10^{-10} \mathrm{~cm}^{3}$ molecule $\mathrm{s}^{-1}$ at $3000 \mathrm{~K}$. Despite a reduced efficiency in product formation due to fast redissociation of the adducts to the reactants at high temperatures, the title reaction can thus be an efficient sink for $\mathrm{HCNO}$ at combustion temperatures in nitrogen-rich environments. At 1 bar and below, $\mathrm{H}_{2} \mathrm{NCO}+\mathrm{NO}$ is the dominant product, with $\mathrm{H}_{2} \mathrm{NCN}+\mathrm{OH}$ and $\mathrm{HCN}+\mathrm{NHOH}$ contributing weakly. This work presents rate coefficients and product distributions for the temperature range $300-3000 \mathrm{~K}$, and pressure range of $10^{-3}$ to $10^{3}$ bar; a brute-force error analysis examines the expected uncertainty interval for these predictions.
\end{abstract}




\section{Introduction}

The mitigation of NOx emissions from combustion systems is critical to improve air quality in many places on the globe. Several mitigation strategies have been proposed, with solutions that encompass fuel additives, reburning, or treatment of flue gases with catalytic converters, with or without further chemicals (e.g. AdBlue based on urea) [1-6]. The HCNO molecule, fulminic acid, is a critical intermediate in NOx reduction [3]. It is formed primarily from the reactions of $\mathrm{HCCO}$ and $\mathrm{CH}_{2}$ with $\mathrm{NO}[3,7-13]$, as:

$$
\begin{aligned}
& \mathrm{HCCO}+\mathrm{NO} \rightarrow \mathrm{HCNO}+\mathrm{CO} \\
& \mathrm{HCCO}+\mathrm{NO} \rightarrow \mathrm{HCN}+\mathrm{CO}_{2}
\end{aligned}
$$

Boullart et al. [11], Eickhoff and Temps [12], and Rim and Hershberger [13] reported values for $\mathrm{k}_{1} /\left(\mathrm{k}_{1}+\mathrm{k}_{2}\right)$ ranging from $0.64 \pm 0.12$ to $0.88 \pm 0.04$, using different experimental techniques. These results showed that channel (1), yielding HCNO, is the dominant pathway. HCNO is also formed by reactions of $\mathrm{NO}$ with ${ }^{3} \mathrm{CH}_{2}$ and ${ }^{1} \mathrm{CH}_{2}$ radicals in the flame [14-16] :

$$
\begin{aligned}
& { }^{3} \mathrm{CH}_{2}\left({ }^{1} \mathrm{CH}_{2}\right)+\mathrm{NO} \rightarrow \mathrm{HCNO}+\mathrm{H} \\
& { }^{3} \mathrm{CH}_{2}\left({ }^{1} \mathrm{CH}_{2}\right)+\mathrm{NO} \rightarrow \mathrm{HCN}+\mathrm{OH}
\end{aligned}
$$

For the ${ }^{3} \mathrm{CH}_{2}+\mathrm{NO}$ reaction, Bauerle et al. [14] measured $\mathrm{H}, \mathrm{O}$, and $\mathrm{OH}$ production rates in shock waves over the temperature range from 1100 to $2600 \mathrm{~K}$ and concluded that (3) and (4) are major product channels, with both rate coefficients increasing with temperature. Later, Grußdorf et al. [16] reported that the dominant channel is $\mathrm{HCNO}+\mathrm{H}$, accounting for about $84 \%$. The physicochemical properties of $\mathrm{HCNO}$, and its reactions with various species present in hydrocarbon combustion such as $\mathrm{H}$ - and $\mathrm{O}$-atoms, $\mathrm{HO}_{\mathrm{x}}$ radicals, and other reactive species have been investigated [3,17-29]. Theoretical studies showed that there are two main mechanisms for the reactions of $\mathrm{HCNO}$, i.e. direct $\mathrm{H}$-abstraction and the association-elimination process, where 
the latter is typically more favorable. For example, in the $\mathrm{HCNO}+\mathrm{OH}$ reaction, the $\mathrm{H}$-abstraction occurs via an energy barrier of $8.7 \mathrm{kcal} \mathrm{mol}^{-1}$ while the channel of $\mathrm{HO}$ addition to the carbon of $\mathrm{HCNO}$ is a barrierless process leading to the major products [28].

The $\mathrm{NH}_{2}$ radical is an interesting coreactant for $\mathrm{HCNO}$, as nitrogen-containing species have been used extensively in NOx reduction strategies, where especially $\mathrm{NH}_{3}$ and $\mathrm{NH}_{3}$-sources such as urea are in use as active components of fuels or flue gas treatment systems. The $\mathrm{NH}_{2}$ radical can be formed by dissociation of $\mathrm{NH}_{3}$ or by its reaction with radical species such as Oatoms, $\mathrm{CH}_{3}, \mathrm{OH}$, etc. $[9,30]$ :

$$
\begin{aligned}
& \mathrm{NH}_{3}+\mathrm{O} \rightarrow \mathrm{NH}_{2}+\mathrm{OH} \\
& \mathrm{NH}_{3}+\mathrm{CH}_{3} \rightarrow \mathrm{NH}_{2}+\mathrm{CH}_{4} \\
& \mathrm{NH}_{3}+\mathrm{OH} \rightarrow \mathrm{NH}_{2}+\mathrm{H}_{2} \mathrm{O}
\end{aligned}
$$

where recommended rate coefficients are $\mathrm{k}_{5}=1.6 \times 10^{-17} \mathrm{~T}^{1.94} \exp (-3250 / \mathrm{T}) \mathrm{cm}^{3}$ molecule $\mathrm{e}^{-1} \mathrm{~s}^{-1}, \mathrm{k}_{6}$ $=1.8 \times 10^{-13} \exp (-5100 / \mathrm{T}) \mathrm{cm}^{3}$ molecule $^{-1} \mathrm{~s}^{-1}$, and $\mathrm{k}_{7}=8.3 \times 10^{-17} \mathrm{~T}^{1.6} \exp (-480 / \mathrm{T}) \mathrm{cm}^{3}$ molecule $^{-1}$ $\mathrm{s}^{-1}[9,30]$.

The title reaction is also of some interest outside of combustion systems. Fulminic acid was detected recent along with its isomer, $\mathrm{HNCO}$, in dark clouds by Marcelino et al. [31]; he also concluded that the reaction of $\mathrm{NO}$ with $\mathrm{CH}_{2}$ radical is a key reaction for the formation of $\mathrm{HCNO}$ in these environments. The $\mathrm{NH}_{2}$ radical has likewise been detected in the interstellar medium [32], is included in chemical models for Titan [e.g. 33], and plays a minor role in the removal of ammonia from earths' atmosphere [34]. Compared to combustion systems, these environments are characterized by lower temperatures and pressures, which may affect the reaction rate and product distribution.

To our knowledge, the cross-reaction of $\mathrm{HCNO}$ with $\mathrm{NH}_{2}$ radicals has not been studied in 
detail before. In this work, we present a quantum chemical characterization of the potential energy surface (PES) of the $\mathrm{HCNO}+\mathrm{NH}_{2}$ reaction, based on which we determine the temperature- and pressure-dependent rate coefficient and product distribution, using theoretical kinetic methodologies. The results are expected to be directly useful for kinetic modeling studies containing the reactants.

\section{Computational Methods}

The potential energy surface (PES) of the $\mathrm{HCNO}+\mathrm{NH}_{2}$ reaction was first characterized using the B3LYP/6-311+G(3df,2p) level of theory [35-37], obtaining the rovibrational characteristics of the reactants, products, intermediates and transition states. Vibrational wavenumbers were used scaled by $0.98[38,39]$. The relative energies were then improved by single point $\operatorname{CCSD}(\mathrm{T}) / 6-311++\mathrm{G}(3 \mathrm{df}, 2 \mathrm{p})$ calculations on the B3LYP geometries [40,41]. The full PES is depicted in the supporting information (figure 2S). Many of the pathways and intermediates are only accessible through very high energy barriers, and play no role in the kinetics of the system. We have selected the kinetically relevant part of the PES, shown in Figure 3 , and further improved the relative energy of the critical points therein by extrapolation to the complete basis set limit (CBS) [42], based on CCSD(T)/aug-cc-pVxD calculations $(x=D, T, Q)$ [43]. To assess the accuracy of such calculations, the heats of formation of main products at 298.15 K are compared against high-accuracy literature data (see Table 1). For most products, this results in deviations between the $6-311++\mathrm{G}(3 \mathrm{df}, 2 \mathrm{p})$ basis set and the CBS limit of less than $1 \mathrm{kcal}$ $\mathrm{mol}^{-1}$, and differences of less than $0.5 \mathrm{kcal} \mathrm{mol}^{-1}$ against reference literature data [44], suggesting that the chosen level of theory is sufficiently accurate to describe the reaction kinetics of the title reaction. This is further corroborated by the low spin contamination in the DFT calculations, 
where $S^{2}$ for doublet states remains below 0.77 even before spin annihilation. Likewise, T1 diagnostic values are always below the upper limit of 0.044 proposed by Rienstra-Karicofe et al. [45,46]: the highest value, T1=0.042, was found for the T0P1 transition state, while all other structures have $\mathrm{T} 1$ diagnostics $\leq 0.040$. The barrierless dissociation of $\mathrm{H}_{2} \mathrm{NCHNO}$ (IS1a) to $\mathrm{H}_{2} \mathrm{NCH}+\mathrm{NO}$ (PR2) was characterized by a set of constrained geometry optimizations at increasing $\mathrm{C}-\mathrm{N}$ atom distances ranging up to $7 \AA$; the energies along this reaction path are further optimized by single point $\operatorname{CCSD}(\mathrm{T}) /$ aug-cc-pVTZ calculations. At the kinetically relevant separations, $\mathrm{S}^{2}$ values of the DFT wavefunction remain $<0.76$ before annihilation, and T1 diagnostics $<0.025$, though higher values are found at short separations below $2 \AA$. To investigate variational kinetic effects in the low T0/1 entrance transition state, IRC calculations were performed using B3LYP, combined with B3LYP frequency calculations and single point $\operatorname{CCSD}(\mathrm{T})$ calculations on the obtained points along the reaction coordinate. These calculations showed increased T1 values reaching 0.044 at reactant separations shorter than the TS saddle point, which itself has a T1 diagnostic of 0.039 ; these higher values could indicate some multireference character in the wave function. All quantum chemical calculations were performed using Gaussian-09 [47].

The reaction of $\mathrm{HNCO}+\mathrm{NH}_{2}$ shows several entrance channels, many of which are not accessible kinetically in practical reaction conditions. For brevity, we only discuss the relevant pathways in this paper, relegating the less accessible pathways to the supporting information. The rate coefficient of the reaction is calculated using canonical transition state theory (CTST) $[48,49]$ for temperatures ranging from 300 to $3000 \mathrm{~K}$; variational effects on the T0/1 entrance TS are studied using canonical variational TST (CVTST) [48,50]. Tunneling is accounted for by asymmetric Eckart tunneling [51,52]. The product distribution is then calculated using RRKM- 
based master equation analysis [53], based on a rigid rotor harmonic oscillator paradigm. The solution method used, CSSPI as implemented in our in-house software [53], is based on a stochastic description of the underlying Monte Carlo random walk of the nascent adducts, yielding product distributions valid at completion of the reaction (i.e. all chemically activated intermediates converted to products or stabilized adducts). This method does not assume steadystate of the intermediate concentrations, though the product yield is also directly valid in steadystate conditions as the concentrations of the intermediates then correspond to the probability distributions inherent in the random walk. It is assumed that the stabilized adducts react primarily with other reactants in the reaction mixture, i.e. unimolecular reactions are expected to be negligibly slow due to the $\sim 40 \mathrm{kcal} \mathrm{mol}^{-1}$ dissociation barriers.

Redissociation of adducts to the free reactants becomes important at higher temperatures, such that the overall rate coefficient shows pressure dependence; the rate coefficient for the adduct formation channel needs to be corrected for this. Collisional energy transfer was described by the Troe biexponential model [54] using $\mathrm{N}_{2}(\varepsilon=97.0 \mathrm{~K}, \sigma=3.617 \AA)$ as a bath gas, and collisional transfer parameters for the $\left[\mathrm{CH}_{2} \mathrm{~N}_{2} \mathrm{O}\right]$ adducts were estimated as $\varepsilon=365.76 \mathrm{~K}, \sigma=$ $3.58 \AA$, and $\Delta \mathrm{E}_{\mathrm{down}}=400 \mathrm{~cm}^{-1}$. The barrierless dissociation channel $\mathrm{H}_{2} \mathrm{NCHNO}$ (IS1a) to $\mathrm{H}_{2} \mathrm{NCH}$ + NO (PR2) was treated by microvariational minimization of the RRKM energy-specific rate coefficients $k(E)$, based on a rigid rotor harmonic oscillator description of the structures, using the rovibrational and energetic properties obtained from the constrained geometries described above.

\section{Results and Discussion}

\section{PES and Reaction Mechanism}

The optimized geometries of the reactants, and of key intermediates, products and 
transition states are shown in Figure 1 and Figure 2, with energetic data listed in Table 2. A simplified PES is depicted in Figure 3, showing the kinetically relevant pathways; a more complete PES can be found in the supporting information (Figures 1S, 2S). Two entrance channels for the $\mathrm{HCNO}+\mathrm{NH}_{2}$ reaction are kinetically relevant. The first is an $\mathrm{H}$-abstraction reaction through transition state $\mathbf{T 0 P 1}$ with a barrier of $10.4 \mathrm{kcal} \mathrm{mol}^{-1}$, forming $\mathrm{CNO}+\mathrm{NH}_{3}$. The second pathway is the addition of the $\mathrm{NH}_{2}$ radical onto the carbon of $\mathrm{HCNO}$, forming $\mathrm{HC}^{\bullet}\left(\mathrm{NH}_{2}\right) \mathrm{NO}$ through T0/1 with an entrance barrier of only $2.2 \mathrm{kcal} \mathrm{mol}^{-1}$. All other entrance transition states have energy above $29 \mathrm{kcal} \mathrm{mol}^{-1}$, making them energetically non-competitive.

The adduct, $\mathrm{HC}^{\bullet}\left(\mathrm{NH}_{2}\right) \mathrm{NO}$, exists in two conformations, IS1a $\left(Z-\mathrm{HC}^{\bullet}\left(\mathrm{NH}_{2}\right) \mathrm{NO}\right)$ and IS1b $\left(E-\mathrm{HC}^{\bullet}\left(\mathrm{NH}_{2}\right) \mathrm{NO}\right)$, which can interconvert through a comparatively high transition state $\mathbf{T 1 a} / \mathbf{1} \mathbf{b}$ for internal rotation. Compared to aliphatic internal rotational barriers, which are typically only a few $\mathrm{kcal} \mathrm{mol}^{-1}, \mathbf{T 1 a} / \mathbf{1 b}$ requires breaking the delocalized $\pi$-system in the $\mathrm{C}^{\bullet}-\mathrm{N}=\mathrm{O}$ moiety, resulting in a rotational barrier of almost $10 \mathrm{kcal} \mathrm{mol}^{-1}$. IS1b can also undergo a facile 1,4-Hmigration forming IS9 $\left(\mathrm{HNCHN}^{\bullet} \mathrm{OH}\right)$. At the nascent energies $>40 \mathrm{kcal} \mathrm{mol}^{-1}$ afforded by the addition process IS1a, IS1b and IS9 will rapidly instate an energy-specific equilibrium, and together constitute the main transient intermediates in this reaction system.

The energetically most favorable fragmentation route of the adducts consists in a multistep reaction starting by a 1,3-H-migration in IS1b, forming IS11 (HNCHNHO ${ }^{\bullet}$ through TS T1/11, followed by 1,4-H-migration through TS T11/10 to the IS10 isomer ( $\left.{ }^{\circ} \mathrm{NCHNHOH}\right)$, and finally decomposing through TS T10P13 to the HCN + NHOH products PR13. The tight H-shift transition states are entropically unfavorable, and $\mathrm{HCN}+\mathrm{HNOH}$ product formation can be expected to face strong competition from the energetically slightly higher decomposition of IS1a/b to singlet $\mathrm{H}_{2} \mathrm{NCH}+{ }^{\bullet} \mathrm{NO}(\mathbf{P R 3})$, either directly or via a TS T1P2 and the post-reactive 
complex COM. Both of these transition states are loose decomposition channels, with a strong entropic advantage compared to the earlier H-migration channels. While the B3LYP level of theory shows dissociation of IS1a to $\mathrm{H}_{2} \mathrm{NCH}+\mathrm{NO}$ (PR3) as a barrierless reaction, $\operatorname{CCSD(T)/aug-cc-pVTZ~energy~calculations~find~a~very~shallow~energy~barrier~to~a~weak~}$ complex, which readily dissociates to the free products (see figure 3S). The dissociation of IS1a is entropically fairly unfavorable, as the fragments form a hydrogen bond between the NO oxygen atom and the $\mathrm{NH}_{2}$ moiety hydrogen atoms.

A third fragmentation pathway with transition states below the energy of the free reactants is the 1,3-H-migration $\mathbf{T 1} / \mathbf{2}$ in IS1b, forming IS2 $\left({ }^{\circ} \mathrm{C}\left(\mathrm{NH}_{2}\right) \mathrm{NOH}\right)$, which readily decomposes to - $\mathrm{OH}+\mathrm{H}_{2} \mathrm{NCN}$ (PR6) through T2P6. The relative energy of the rate-limiting transition states of the above three fragmentation channels are all within $6 \mathrm{kcal} \mathrm{mol}^{-1}$, such that the rovibrational properties will have a deciding impact on the relative rates.

For completeness, we also indicate the formation of $\mathbf{P R 3}\left(\mathrm{HNC}^{\bullet} \mathrm{NO}+\mathrm{H}_{2}\right)$ from IS9 through T9P3, though this TS protrudes above the energy of the free reactants by over $8 \mathrm{kcal}$ $\mathrm{mol}^{-1}$, and is not expected to be competitive with the earlier three fragmentation channels. The supporting information shows a large number of additional intermediates and isomerisation transition states (Figure 1S, 2S). These intermediates are only formed through energetically and/or entropically highly unfavorable channels (see Table 5S), such that they are expected to have a low contribution to the $\left[\mathrm{CH}_{2} \mathrm{~N}_{2} \mathrm{O}\right]$ population, and none allow access to low-lying fragmentation channels that are reasonably expected to compete effectively against the channels discussed above. As such, we omit a detailed discussion in this work; a full dataset can be found in the supporting information. 


\section{Rate constant and product distribution calculations}

The rate coefficient and product distribution were calculated for the temperature range 300 to $3000 \mathrm{~K}$ and pressures ranging from $10^{-3}$ to $10^{3}$ bar. The only two channels contributing to product formation are the addition channel through $\mathbf{T 0 / 1}$, and the $\mathrm{H}$-abstraction channel through T0P1, owing to the high entrance barriers of all other channels. While the temperature dependence of the rate coefficient for the overall reaction is minor (see Figure 4), the contribution of these two channels depends strongly on the temperature. At lower temperatures, reaction by Habstraction (T0P1) is negligible, but starts to contribute at higher temperatures, $>2000 \mathrm{~K}$. In these latter conditions, we also find that the adducts formed through T0_1 partially redissociate to the free reactants, reducing the effective contribution to the product yield of this channel, thereby further enhancing the relative formation of $\mathrm{CNO}+\mathrm{NH}_{3}$ (PR1) through $\mathbf{T 0 P 1}$. At $3000 \mathrm{~K}$ and low pressure, as much as $80 \%$ of the adducts formed are lost through redissociation, which also reduces the effective overall rate coefficient $k(T)$ for product formation; this is accounted for in our results. At low temperature, or at high pressures, redissociation is significantly less or negligible. For the temperatures considered in this study, the corrected rate coefficient is not overly dependent on the pressure, changing at most by a factor 1.5 across the considered pressure range; this variation is rather small compared to the uncertainty on the rate coefficient predictions, such that we can average the effective rate coefficient across all pressures without loss of statistically meaningful information. Fitting the resulting rate coefficients then yields the following Kooij expression:

$$
k_{\mathrm{HCNO}+\mathrm{NH}_{2}}(T)=1.36 \times 10^{-15} T^{1.40} \exp (170 \mathrm{~K} / T) \mathrm{cm}^{3} \text { molecule } \mathrm{s}^{-1}
$$

which ranges from $k(3000 \mathrm{~K})=1.1 \times 10^{-10} \mathrm{~cm}^{3}$ molecule $\mathrm{s}^{-1}$, down to $k(300 \mathrm{~K})=7.2 \times$ $10^{-12} \mathrm{~cm}^{3}$ molecule $\mathrm{s}^{-1}$ 
The product distribution of the $\mathrm{HCNO}+\mathrm{NH}_{2}$ reaction is more complex, as changes in temperature and pressure have a profound impact on the competition between the various channels (see Figure 5). Adduct formation through $\mathbf{T 0 / 1}$ is the main entrance channel, in agreement with the low entrance barrier to this channel. As already indicated, these adducts redissociate for a large fraction to the free reactants at high temperatures, allowing $\mathrm{NH}_{3}+\mathrm{CNO}$ (PR1) formation through T0P1 to contribute up to $40 \%$ of the effective product formation at 3000 $\mathrm{K}$. The high impact of redissociation of the adducts, up to $80 \%$ in low-pressure, high-temperature reaction condition, is surprising given that the PES shows several exit channels below the entrance channel. Formation of $\mathrm{NO}+\mathrm{H}_{2} \mathrm{NCO}(\mathbf{P R 2})$ is the dominant product formation channel, but is only a few $\mathrm{kcal} \mathrm{mol}^{-1}$ below the entrance channel. This dissociation has an exit barrier (T1P2), which is however lowered strongly when the $\mathrm{NO}$ and $\mathrm{H}_{2} \mathrm{NCH}$ fragments in the PR2 product channel interact by $\mathrm{H}$-bonding during the dissociation, as in the IS1a $\rightarrow$ PR2 dissociation. This allows for an energetically more favorable, barrierless dissociation, but the stronger fragment interaction also leads to a more rigid, entropically less favorable reaction, reducing the state densities and concomitantly the energy-specific rate coefficients for $\mathrm{NO}+$ $\mathrm{H}_{2} \mathrm{NCO}$ (PR2) formation. At high internal energies (i.e. at high temperatures), where the energy difference between $\mathbf{P R 2}$ and T0/1 has relatively less impact, the entropic advantage then favors redissociation to $\mathrm{HCNO}+\mathrm{NH}_{2}$. At lower internal energies (i.e. low temperatures, or fast energy loss in collisions with the bath gas), redissociation becomes less prominent.

While formation of $\mathrm{HCN}+\mathrm{NHOH}(\mathbf{P R 1 3})$ is energetically slightly more favorable than PR2 formation, it is only accessible through three consecutive tight transition states (T1/11, T11/10, and T10P13), which furthermore are energetically only a few kcal $\mathrm{mol}^{-1}$ below the PR2 
exit channels, making formation of PR13 less competitive, with a maximum yield of $11.4 \%$. The energetically most favorable product formed from the nascent adduct is $\mathrm{OH}+\mathrm{H}_{2} \mathrm{NCN}$ (PR6); however, its formation proceeds through the energetically high TS T1/2, rendering PR6 formation ineffective, with a maximum contribution of $5.3 \%$. All other products characterized in this work (see Figure 3 and supporting information) are formed over energetically high transition states, and can be neglected in all conditions considered.

The collisional stabilisation of the adducts is affected by their lifetime, where rapid isomerisation between IS1a, IS1b, and IS9 yields a high effective state density for the adducts, slowing down unimolecular decomposition, and allowing collisional thermalisation at pressures at low as 10 bar even at 1000K. Stabilisation of IS10 is negligible in all conditions considered, while stabilisation of IS11 has a maximum contribution of 6.3\%. At higher pressures, IS1a, IS1b and IS9 are the dominant products; rapid isomerisation during the collisional thermalisation process allows these adducts to contribute in yields that closely follow their energy-specific steady-state ratios.

The supporting information tabulates all results as a function of temperature and pressure (Tables 6S and 7S). We also provide analytical fits for the product yields for the low-pressure regime, 1 bar, and 100 bar, and a set of interpolation equations valid for reaction conditions relevant for combusions $(\mathrm{T}=700-2000 \mathrm{~K}, \mathrm{P}=1$ to $100 \mathrm{bar})$.

\section{Error analysis}

To assess the uncertainties of the predictions, we performed a brute force error analysis for the rate coefficient and product distribution. The variables with the largest impact on our predictions are the energies of the entrance channels and the transition states for product 
formation from the adducts, as well as the average energy transferred in a collision with the bath gas. The energy of the reaction enthalpies compares within $0.5 \mathrm{kcal} \mathrm{mol}^{-1}$ against literature data (see Table 1), but the transition states are expected to have a somewhat higher uncertainty. The energies of transition state T0/1, T0P1, TS10P13, TS11_10, TS1_11, TS1_2, and TS1P2 were thus varied by $1 \mathrm{kcal} \mathrm{mol}^{-1}$, both up and downward. Likewise, the energy of the PR2 product dissociation limit was varied by $1 \mathrm{kcal} \mathrm{mol}^{-1}$ up and down. The collisional energy transfer parameter, on the other hand, is estimated by analogy with similar molecules, and in the absence of experimental calibration data carries a large uncertainty. We therefore vary the value for $\Delta \mathrm{E}_{\text {down }}$ by $40 \%$ in both directions. Finally, for the low entrance transition state T0/1, we examine the impact of variational effects, by minimizing the predicted rate coefficient for $\mathrm{HNCO}+\mathrm{NH}_{2}$ reaction along a ZPE-corrected IRC path for the T0/1 saddle point; this source of error is only included in the error analysis of the overall rate coefficient. Variational effects are active mostly at higher temperatures $>1000 \mathrm{~K}$, where it can reduce the rate coefficient by over a factor of 3 by tightening the kinetic bottleneck at higher internal energies. This rate reduction is mitigated by a concomitant reduction in the redissociation of the nascent adducts, thus increasing the efficiency of product formation and hence the effective rate coefficient. In this work, we use the averaged variational effects obtained by CVTST calculations using B3LYP, CCSD(T)//B3LYP, M06-2X, and $\operatorname{CCSD}(\mathrm{T}) / / \mathrm{M} 06-2 \mathrm{X}$ calculations.

The deviations obtained relative to the parent calculations were then combined by summing the variances, i.e. $\sigma_{\text {tot }}=\left(\Sigma\left(\sigma_{\mathrm{i}}\right)^{2}\right)^{0.5}$. For each parameter, the largest impact across the up and down variation was selected as the symmetrized uncertainty interval for that parameter; this avoids underestimating the error. This type of error analysis is only valid if the errors are independent, linear, and not too large relative to the predicted values. Given that product fractions 
are dependent and non-linear, these conditions are not fully met for the case at hand, but the obtained uncertainties are nonetheless expected to represent a reasonable assessment of the expected errors.

Figure 4 and Figure 6 show the uncertainties on the predictions. The uncertainty on the total rate coefficient is governed mostly by the entrance barrier height, where $1 \mathrm{kcal} \mathrm{mol}^{-1}$ variation induces an uncertainty of a factor of 5.4 at room temperature (see Figure 4). At higher temperatures, the broadening Boltzmann distribution reduces the impact of these parameters, and the rate prediction becomes increasingly more reliable. The uncertainty interval is generally asymmetric, as optimization of the entrance TS description tend to decrease the rate coefficient, e.g. by variational effects.

The largest impact on the product distribution predictions is due to the $\Delta \mathrm{E}_{\text {down }}$ parameter in the energy transfer model, especially in the fall-off regions where stabilisation occurs at similar rates as fragmentation. The uncertainty on this competition is clearly seen in Figure 6, where the highest errors on stabilization yield (IS1a, IS1b, IS9 and IS11) and dissociation yield $\left(\mathrm{H}_{2} \mathrm{NCH}+\mathrm{NO}\left(\right.\right.$ PR2), $\mathrm{OH}+\mathrm{H}_{2} \mathrm{NCN}($ PR6) and $\mathrm{HCN}+\mathrm{NHOH}($ PR13)) follow the main fall-off region from 1 bar at $300 \mathrm{~K}$ to 100 bar at $1000 \mathrm{~K}$. $\mathrm{CNO}+\mathrm{NH}_{3}(\mathbf{P R 1})$ formation occurs only at high temperatures, and is mostly dependent on the relative energy of the entrance transition states T0_1 and T0P1, irrespective of pressure. At pressures even higher than considered here, the yield of $\mathrm{CNO}+\mathrm{NH}_{3}$ would also become pressure-dependent and thus sensitive to the $\Delta \mathrm{E}_{\text {down }}$ parameter.

At low temperatures, characterized by a narrow nascent energy distribution near the energy of the reactants, the relative yields of the fragmentation products become sensitive to the relative energy of the entrance and exit transition states; at higher temperatures, the energy distribution broadens, reducing the sensitivity. The supporting information lists the uncertainties 
as a function of temperature and pressure across the entire range of reaction conditions examined (Table 6S and 7S)

\section{Reverse reaction: $\mathrm{H}_{2} \mathrm{NCO}+\mathrm{NO}$}

As $\mathrm{H}_{2} \mathrm{NCO}$ is the main product radical of the title reactant, it is useful to examine if it could be an efficient sink of NO in a NOx reduction strategy. The expected products of such a reaction would be stabilization of the IS1a, IS1b and IS9 adducts. While the $\mathrm{H}_{2} \mathrm{NCO}+\mathrm{NO}$ reaction is formally barrierless, it is entropically highly unfavorable; as already discussed higher, this is due to the formation of strong, pre-reactive interactions between the moieties leading to rigid structures. While a looser entrance channel exists that forgoes this $\mathrm{H}$-bonding, this pathway show a distinct energy barrier of $10.6 \mathrm{kcal} \mathrm{mol}^{-1}$, and does not contribute significantly. The entropic hindrance strongly reduces the rate coefficient, with a rate coefficient $<7 \times 10^{-13} \mathrm{~cm}^{3}$ molecule $^{-1} \mathrm{~s}^{-1}$ even at $2000 \mathrm{~K}$; an $E, J$-micro-variational transition state theory calculation of $k(T)$ yields the following Kooij equation:

$$
k_{\mathrm{H}_{2} \mathrm{NCO}+\mathrm{NO}}(T)=3.84 \times 10^{-21} T^{2.45} \exp (746 \mathrm{~K} / T) \mathrm{cm}^{3} \text { molecule }^{-1} \mathrm{~s}^{-1}
$$

Given the low rate coefficient, and the concomitant low impact of this reaction, we did not perform a product study.

\section{Conclusions}

The reaction of $\mathrm{HCNO}$ with $\mathrm{NH}_{2}$ was studied using quantum chemical and theoretical kinetic methodologies. The reaction is found to be moderately fast with rate coefficients exceeding $1 \times 10^{-11} \mathrm{~cm}^{3}$ molecule $\mathrm{s}^{-1} \mathrm{~s}^{-1}$ at combustion temperatures, making this reaction a potential loss process of the HCNO intermediate in combustion systems. 


$$
k_{\mathrm{HCNO}+\mathrm{NH}_{2}}(T)=1.36 \times 10^{-15} T^{1.40} \exp (170 \mathrm{~K} / T) \mathrm{cm}^{3} \text { molecule }^{-1} \mathrm{~s}^{-1}
$$

At low temperatures, such as in the interstellar medium, the reaction appears too slow to contribute, owing to the (small) entrance energy barrier. The product distribution of the reaction is complex, with stabilization of the $\mathrm{CH}_{3} \mathrm{~N}_{2} \mathrm{O}$ adducts at high pressures $>100$ bar, while at 1 bar $\mathrm{H}_{2} \mathrm{NCH}+\mathrm{NO}$ are the dominant products, contributing $85 \%$ at $1000 \mathrm{~K}$, with $\mathrm{H}_{2} \mathrm{NCN}+\mathrm{OH}(5 \%)$ and $\mathrm{HCN}+\mathrm{NHOH}(10 \%)$ contribution weakly. Formation of $\mathrm{NH}_{3}+\mathrm{CNO}$ only contributes somewhat above $2500 \mathrm{~K}$, whereas all other products are typically negligible.

The impact of the $\mathrm{NH}_{2}+\mathrm{HCNO}$ reaction on the $\mathrm{HCNO}$ budget or the NOx reduction potential in a combustion system will strongly depend on the reaction mixture. The HCNO loss processes typically included in combustion models are the reactions with $\mathrm{H}, \mathrm{O}$, and $\mathrm{OH}$, and unimolecular decomposition to $\mathrm{HCN}+\mathrm{O}$ [e.g. 55-62]. These reactions have rate coefficients ranging from $1 \times 10^{-12}$ to $\geq 1 \times 10^{-10} \mathrm{~cm}^{3}$ molecule $\mathrm{s}^{-1}$, i.e. up to an order of magnitude faster than the reaction with $\mathrm{NH}_{2}$. In standard hydrocarbon combustion, it is thus not expected that the title reaction is affecting the chemistry strongly. However, for fuels with a high content of nitrogencontaining compounds such as $\mathrm{NH}_{3}$, urea, and other compounds, either as part of the fuel or as an flue gas treatment additive, the $\mathrm{NH}_{2}$ radical concentration can become comparable to the mole fractions of the other HCNO co-reactants, increasing the importance of the title reaction, and thus regenerating $\mathrm{NO}$ originally captured in the $\mathrm{HCCO}$ or $\mathrm{CH}_{2}+\mathrm{NO}$ reaction producing the parent $\mathrm{HCNO}$ reactant. Including the $\mathrm{HCNO}+\mathrm{NH}_{2}$ reaction in modeling of actual combustion systems is thus the only way to quantify the possible impact of the current work; this is outside the scope of the current work. The reaction of $\mathrm{H}_{2} \mathrm{NCH}+\mathrm{NO}$ is expected to be of negligible influence in typical combustion systems, owing to a low rate coefficients even at elevated temperatures. 


\section{Acknowledgements:}

We thank the National Foundation for Science and Technology Development (Nafosted),

Vietnam, which has sponsored this work under project number 104.06-2014.78.

\section{References}

[1] J.A. Miller, C.T. Bowman, Kinetic Modeling of the Reduction of Nitric-Oxide in Combustion Products, Int. J. Chem. Kinet. 23 (1991) 289-313. doi:10.1002/kin.550230403.

[2] J.A. Miller, C.T. Bowman, Mechanism and Modeling of Nitrogen Chemistry in Combustion, Prog. Energy Combust. Sci. 15 (1989) 287-338. doi:10.1016/0360-1285(89)90017-8.

[3] J.A. Miller, S.J. Klippenstein, P. Glarborg, A kinetic issue in reburning: The fate of HCNO, Combust. Flame. 135 (2003) 357-362. doi:10.1016/j.combustflame.2003.07.002.

[4] J.O.L. Wendt, C.V. Sternling, M.A. Matovich, Reduction of sulfur trioxide and nitrogen oxides by secondary fuel injection, Symp. Int. Combust. 14 (1973) 897-904. doi:10.1016/S0082-0784(73)80082-7.

[5] L.J. Muzio, J.K. Arand, D.P. Teixeira, Gas phase decomposition of nitric oxide in combustion products, Symp. Int. Combust. 16 (1977) 199-208. doi:10.1016/S00820784(77)80325-1.

[6] A.L. Myerson, The reduction of nitric oxide in simulated combustion effluents by hydrocarbon-oxygen mixtures, Symp. Int. Combust. 15 (1975) 1085-1092. doi:10.1016/S0082-0784(75)80373-0.

[7] L. Vereecken, R. Sumathy, S.A. Carl, J. Peeters, NOx reduction by reburning: theoretical study of the branching ratio of the HCCO+NO reaction, Chem. Phys. Lett. 344 (2001) 400406. doi:10.1016/S0009-2614(01)00818-1.

[8] S.A. Carl, Q. Sun, L. Vereecken, J. Peeters, Absolute Rate Coefficient of the HCCO + NO Reaction over the Range T = 297-802 K, J. Phys. Chem. A. 106 (2002) 12242-12247. doi:10.1021/jp014135i.

[9] W.C. Gardiner, ed., Gas-phase combustion chemistry, Springer, New York, 2000.

[10] W.C. Zhang, B.N. Du, C.J. Feng, Theoretical investigation of reaction mechanism for $\mathrm{CH}_{2}\left(\mathrm{X}^{3} \mathrm{~B}_{1}\right)$ with NO radical, J. Mol. Struct.-Theochem. 679 (2004) 121-125. doi:10.1016/j.theochem.2004.04.012.

[11] W. Boullart, M.T. Nguyen, J. Peeters, Experimental Investigation of the Reaction Between Nitric-Oxide and Ketenyl Radicals (HCCO+NO) - Rate Coefficient at T=290-670-K and Product Distribution at 700-K, J. Phys. Chem. 98 (1994) 8036-8043. doi:10.1021/j100084a020.

[12] U. Eickhoff, F. Temps, FTIR study of the products of the reaction between HCCO and NO, Phys. Chem. Chem. Phys. 1 (1999) 243-251. doi:10.1039/a807258b.

[13] K.T. Rim, J.F. Hershberger, Product branching ratio of the HCCO plus NO reaction, J. Phys. Chem. A. 104 (2000) 293-296. doi:10.1021/jp9922209.

[14] S. Bauerle, M. Klatt, H. Gg. Wagner, Investigation of the Reaction of ${ }^{3} \mathrm{CH}_{2}$ with NO at high Temperatures, Berichte Bunsenges. Für Phys. Chem. 99 (1995) 97-104. doi:10.1002/bbpc.19950990202. 
[15] D.L. Baulch, C.T. Bowman, C.J. Cobos, R.A. Cox, T. Just, J.A. Kerr, M.J. Pilling, D. Stocker, J. Troe, W. Tsang, R.W. Walker, J. Warnatz, Evaluated Kinetic Data for Combustion Modeling: Supplement II, J. Phys. Chem. Ref. Data. 34 (2005) 757. doi:10.1063/1.1748524.

[16] J. Grußdorf, F. Temps, H.G. Wagner, An FTIR Study of the Products of the Reaction between $\mathrm{CH}_{2}\left(\mathrm{X}^{3} \mathrm{~B}_{1}\right)$ and NO, Berichte Bunsenges. Für Phys. Chem. 101 (1997) 134-138. doi:10.1002/bbpc.19971010118.

[17] S. Wang, J.-K. Yu, D.-J. Ding, C.-C. Sun, Theoretical study on the mechanism of OH + HCNO reaction, Theor. Chem. Acc. 118 (2007) 337-345. doi:10.1007/s00214-007-0262-1.

[18] W.H. Feng, J.P. Meyer, J.F. Hershberger, Kinetics of the OH +HCNO reaction, J. Phys. Chem. A. 110 (2006) 4458-4464. doi:10.1021/jp058305t.

[19] W. Feng, J.F. Hershberger, Product channels in the 193-nm photodissociation of HCNO (fulminic acid), Chem. Phys. 472 (2016) 18-23. doi:10.1016/j.chemphys.2016.02.017.

[20] W. Feng, J.F. Hershberger, Kinetics of the O+HCNO reaction, J. Phys. Chem. A. 111 (2007) 10654-10659. doi:10.1021/jp075636s.

[21] W. Feng, J.F. Hershberger, Kinetics of the NCO +HCNO reaction, J. Phys. Chem. A. 111 (2007) 3831-3835. doi:10.1021/jp066036g.

[22] W. Feng, J.F. Hershberger, Theoretical study of the $\mathrm{O}\left({ }^{3} \mathrm{P}\right)+\mathrm{HCNO}$ reaction, Chem. Phys. Lett. 457 (2008) 307-311. doi:10.1016/j.cplett.2008.04.012.

[23] W. Feng, J.F. Hershberger, Kinetics of the CN+HCNO reaction, J. Phys. Chem. A. 110 (2006) 12184-12190. doi:10.1021/jp0650073.

[24] X.-J. Jia, Y.-J. Liu, J.-Y. Sun, H. Sun, F. Wang, X.-M. Pan, R.-S. Wang, Theoretical study on the singlet and triplet potential energy surfaces of $\mathrm{NH}\left(\mathrm{X}^{3} \mathrm{~S}^{-}\right)+\mathrm{HCNO}$ reaction, Theor. Chem. Acc. 127 (2010) 49-56. doi:10.1007/s00214-009-0707-9.

[25] P.B. Karadakov, D.L. Cooper, J. Gerratt, Modern valence-bond description of chemical reaction mechanisms: the 1,3-dipolar addition of fulminic acid to ethyne, Theor. Chem. Acc. 100 (1998) 222-229. doi:10.1007/s002149800m52.

[26] Y. Li, C. Chen, X. Wang, L. Wang, J. Zhang, The mechanism research on the reaction $\mathrm{HCNO}+\mathrm{HO}_{2}$ : a theoretical investigation, Theor. Chem. Acc. 135 (2016) 1-8. doi:10.1007/s00214-016-1858-0.

[27] Y. Li, H. Liu, Y. Sun, Z. Li, X. Huang, C. Sun, Radical reaction HCNO $+{ }^{3} \mathrm{NH}$ : a mechanistic study, Theor. Chem. Acc. 124 (2009) 123-137. doi:10.1007/s00214-009-05913.

[28] H.M.T. Nguyen, T.N. Nguyen, Calculations on the complex mechanism of the HCNO + OH reaction, Chem. Phys. Lett. 599 (2014) 15-22. doi:10.1016/j.cplett.2014.03.001.

[29] Y. Xin, M. Zhao, Z. Li, W. Xiong, X. Song, H. Hou, B. Wang, Theoretical Investigation of the Reaction of Imidogen with Fulminic Acid, J. Chem. Theory Comput. 5 (2009) 20212029. doi:10.1021/ct9002288.

[30] F. Westley, Table of recommended rate constants for chemical reactions occurring in combustion, National Bureau of Standards, Gaithersburg, MD, 1980. doi:10.6028/NBS.NSRDS.67.

[31] N. Marcelino, J. Cernicharo, B. Tercero, E. Roueff, Discovery of Fulminic Acid, HCNO, in Dark Clouds, Astrophys. J. Lett. 690 (2009) L27-L30. doi:10.1088/637X/690/1/L27.

[32] E.F. Van Dishoeck, D.J. Jansen, P. Schilke, T.G. Phillips, Detection of the Interstellar $\mathrm{NH}_{2}$ Radical, Astrophys. J. 416 (1993) L83-L86. doi:10.1086/187076.

[33] J.C. Loison, E. Hebrard, M. Dobrijevic, K.M. Hickson, F. Caralp, V. Hue, G. Gronoff, O. 
Venot, Y. Benilan, The neutral photochemistry of nitriles, amines and imines in the atmosphere of Titan, Icarus. 247 (2015) 218-247. doi:10.1016/j.icarus.2014.09.039.

[34] P. Warneck, Chemistry of the natural atmosphere, Academic Press, San Diego, 1988.

[35] A.D. Becke, A New Mixing of Hartree-Fock and Local Density-Functional Theories, J. Chem. Phys. 98 (1993) 1372-1377. doi:10.1063/1.464304.

[36] A.D. Becke, Density-functional thermochemistry. II. The effect of the Perdew-Wang generalized-gradient correlation correction, J. Chem. Phys. 97 (1992) 9173-9177. doi:10.1063/1.463343.

[37] C. Lee, W. Yang, R.G. Parr, Development of the Colle-Salvetti correlation-energy formula into a functional of the electron density, Phys. Rev. B. 37 (1988) 785-789. doi:10.1103/PhysRevB.37.785.

[38] J.L. Bao, J. Zheng, I.M. Alecu, B.J. Lynch, Y. Zhao, D.G. Truhlar, Database of Frequency Scale Factors for Electronic Model Chemistries (Version 3 Beta 2), (n.d.). http://comp.chem.umn.edu/freqscale/index.html.

[39] I.M. Alecu, J. Zheng, Y. Zhao, D.G. Truhlar, Computational Thermochemistry: Scale Factor Databases and Scale Factors for Vibrational Frequencies Obtained from Electronic Model Chemistries, J. Chem. Theory Comput. 6 (2010) 2872-2887. doi:10.1021/ct100326h.

[40] J.A. Pople, M. Head-Gordon, K. Raghavachari, Quadratic configuration interaction. A general technique for determining electron correlation energies, J. Chem. Phys. 87 (1987) 5968. doi:10.1063/1.453520.

[41] J.D. Watts, J. Gauss, R.J. Bartlett, Coupled-cluster methods with noniterative triple excitations for restricted open-shell Hartree-Fock and other general single determinant reference functions. Energies and analytical gradients, J. Chem. Phys. 98 (1993) 8718-8733. doi:10.1063/1.464480.

[42] J.M.L. Martin, Ab initio total atomization energies of small molecules - towards the basis set limit, Chem. Phys. Lett. 259 (1996) 669-678. doi:10.1016/0009-2614(96)00898-6.

[43] T.H. Dunning, Gaussian basis sets for use in correlated molecular calculations. I. The atoms boron through neon and hydrogen, J. Chem. Phys. 90 (1989) 1007-1023. doi:10.1063/1.456153.

[44] B. Ruscic, Active Thermochemical Tables (ATcT) values based on ver. 1.118 of the Thermochemical Network (2015); available at ATcT.anl.gov, Argonne Natl. Lab. Act. Thermochem. Tables. (n.d.). http://atct.anl.gov/ (accessed November 10, 2016).

[45] T.J. Lee, P.R. Taylor, A diagnostic for determining the quality of single-reference electron correlation methods, Int. J. Quantum Chem. 36 (1989) 199-207. doi:10.1002/qua.560360824.

[46] J.C. Rienstra-Kiracofe, W.D. Allen, H.F. Schaefer, The $\mathrm{C}_{2} \mathrm{H}_{5}+\mathrm{O}_{2}$ Reaction Mechanism: High-Level ab Initio Characterizations, J. Phys. Chem. A. 104 (2000) 9823-9840. doi:10.1021/jp001041k.

[47] M.J. Frisch, G.W. Trucks, H.B. Schlegel, G.E. Scuseria, M.A. Robb, J.R. Cheeseman, G. Scalmani, V. Barone, B. Mennucci, G.A. Petersson, H. Nakatsuji, M. Caricato, X. Li, H.P. Hratchian, A.F. Izmaylov, J. Bloino, G. Zheng, J.L. Sonnenberg, M. Hada, M. Ehara, K. Toyota, R. Fukuda, J. Hasegawa, M. Ishida, T. Nakajima, Y. Honda, O. Kitao, H. Nakai, T. Vreven, J.A. Montgomery Jr., J.E. Peralta, F. Ogliaro, M. Bearpark, J.J. Heyd, E. Brothers, K.N. Kudin, V.N. Staroverov, T. Keith, R. Kobayashi, J. Normand, J. Normand, K. Raghavachari, A. Rendell, J.C. Burant, S.S. Iyengar, J. Tomasi, M. Cossi, N. Rega, J.M. Millam, M. Klene, J.E. Knox, J.B. Cross, V. Bakken, C. Adamo, J. Jaramillo, R. Gomperts, 
R.E. Stratmann, O. Yazyev, A.J. Austin, R. Cammi, C. Pomelli, J.W. Ochterski, R.L. Martin, K. Morokuma, V.G. Zakrzewski, G.A. Voth, P. Salvador, J.J. Dannenberg, S. Dapprich, A.D. Daniels, O. Farkas, J.B. Foresman, J.V. Ortiz, J. Cioslowski, D.J. Fox, J.A. Pople, Gaussian 09, Revision B.01, Gaussian Inc., Wallington CT, 2010.

[48] D.G. Truhlar, B.C. Garrett, Variational Transition State Theory, Annu. Rev. Phys. Chem. 35 (1984) 159-189. doi:10.1146/annurev.pc.35.100184.001111.

[49] D.G. Truhlar, B.C. Garrett, S.J. Klippenstein, Current Status of Transition-State Theory, J. Phys. Chem. 100 (1996) 12771-12800. doi:10.1021/jp953748q.

[50] B.C. Garrett, D.G. Truhlar, Variational transition state theory, in: Theory Appl. Comput. Chem., 1st ed, Elsevier, Amsterdam; Boston, 2005: pp. 67-87. http://linkinghub.elsevier.com/retrieve/pii/B9780444517197500482 (accessed January 23, 2015).

[51] C. Eckart, The penetration of a potential barrier by electrons, Phys. Rev. 35 (1930) 13031309. doi:10.1103/PhysRev.35.1303.

[52] H.S. Johnston, J. Heicklen, Tunneling corrections for unsymmetrical Eckart potential energy barriers, J. Phys. Chem. 66 (1962) 532-533. doi:10.1021/j100809a040.

[53] L. Vereecken, G. Huyberechts, J. Peeters, Stochastic simulation of chemically activated unimolecular reactions, J. Chem. Phys. 106 (1997) 6564-6573. doi:10.1063/1.473656.

[54] J. Troe, Theory of Thermal Unimolecular Reactions at Low-Pressures. 1. Solutions, J. Chem. Phys. 66 (1977) 4745-4757. doi:10.1063/1.433837.

[55] M.D. Bohon, M.J. Al Rashidi, S.M. Sarathy, W.L. Roberts, Experiments and simulations of NOx formation in the combustion of hydroxylated fuels, Combust. Flame. 162 (2015) 23222336. doi:10.1016/j.combustflame.2015.01.022.

[56] A.A. Konnov, J. De Ruyck, Kinetic modeling of the thermal decomposition of ammonia, Combust. Sci. Technol. 152 (2000) 23-37. doi:10.1080/00102200008952125.

[57] A.A. Konnov, Implementation of the NCN pathway of prompt-NO formation in the detailed reaction mechanism, Combust. Flame. $156 \quad$ (2009) 2093-2105. doi:10.1016/j.combustflame.2009.03.016.

[58] N. Lamoureux, H. El Merhubi, L. Pillier, S. de Persis, P. Desgroux, Modeling of NO formation in low pressure premixed flames, Combust. Flame. 163 (2016) 557-575. doi:10.1016/j.combustflame.2015.11.007.

[59] N. Lamoureux, K. Marschallek-Watroba, P. Desgroux, J.-F. Pauwels, M.D. Sylla, L. Gasnot, Measurements and modelling of nitrogen species in $\mathrm{CH}_{4} / \mathrm{O}_{2} / \mathrm{N}_{2}$ flames doped with $\mathrm{NO}, \mathrm{NH}_{3}$, or $\mathrm{NH}_{3}+\mathrm{NO}$, Combust. Flame. 176 (2017) 48-59. doi:10.1016/j.combustflame.2016.10.019.

[60] A.V. Sepman, S.E. Abtahizadeh, A.V. Mokhov, J.A. van Oijen, H.B. Levinsky, L.P.H. de Goey, Numerical and experimental studies of the NO formation in laminar coflow diffusion flames on their transition to MILD combustion regime, Combust. Flame. 160 (2013) 13641372. doi:10.1016/j.combustflame.2013.02.027.

[61] Z. Tian, Y. Li, L. Zhang, P. Glarborg, F. Qi, An experimental and kinetic modeling study of premixed $\mathrm{NH}_{3} / \mathrm{CH}_{4} / \mathrm{O}_{2} / \mathrm{Ar}$ flames at low pressure, Combust. Flame. 156 (2009) 1413-1426. doi:10.1016/j.combustflame.2009.03.005.

[62] H. Xiao, A. Valera-Medina, P.J. Bowen, Modeling Combustion of Ammonia/Hydrogen Fuel Blends under Gas Turbine Conditions, Energy Fuels. 31 (2017) 8631-8642. doi:10.1021/acs.energyfuels.7b00709. 


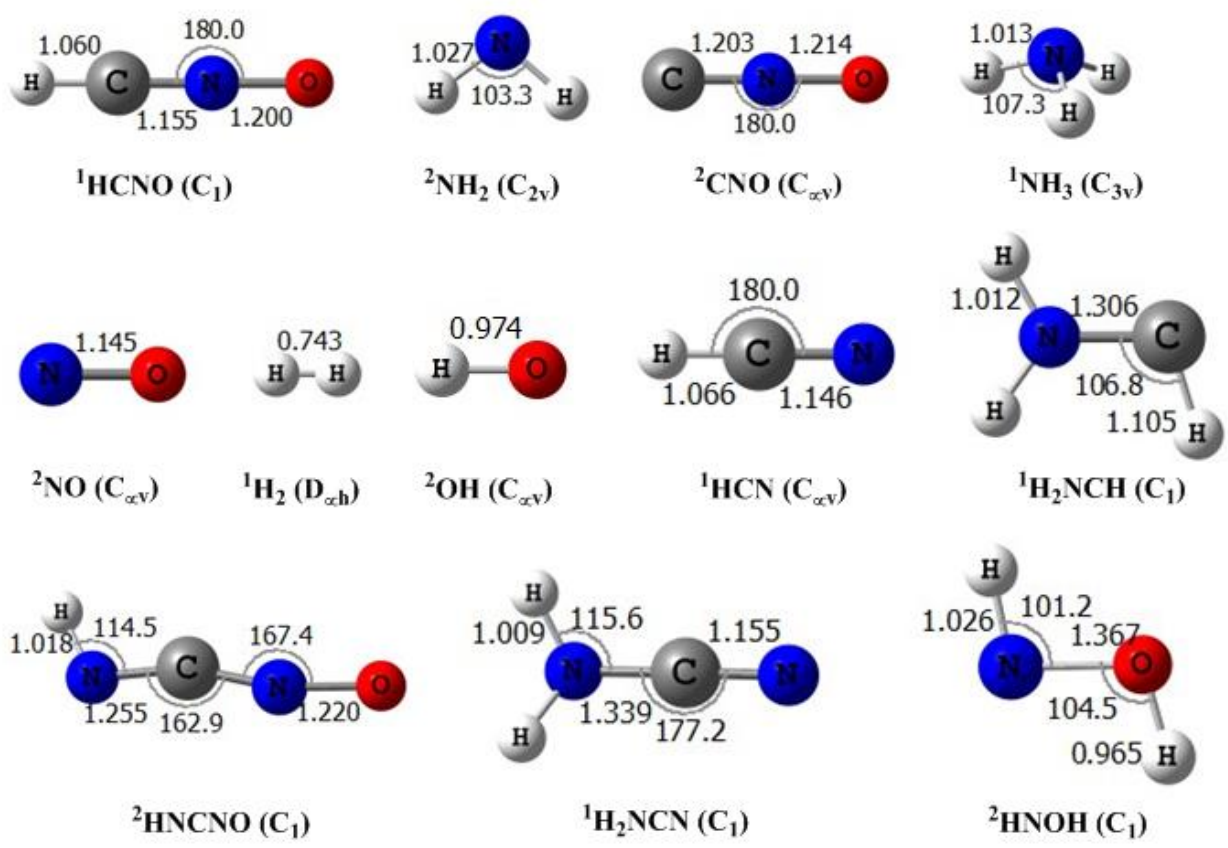

Figure 1: Geometries of the main reactants and products involved in the $\mathrm{HCNO}+\mathrm{NH}_{2}$ reaction, optimized at the B3LYP/6-311++G(3df,2p) level of theory. (Bond lengths in $\AA$ and angles in degree). Molecular point groups are indicated in parentheses. 


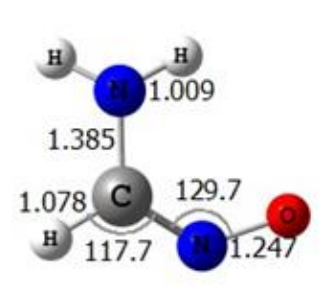

IS1a $\left(C_{1}\right)$

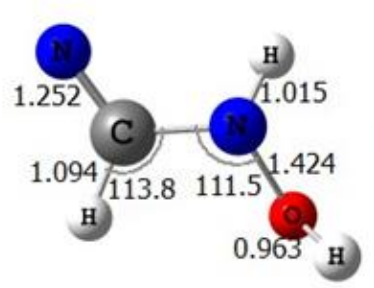

$\operatorname{IS10}\left(\mathrm{C}_{1}\right)$

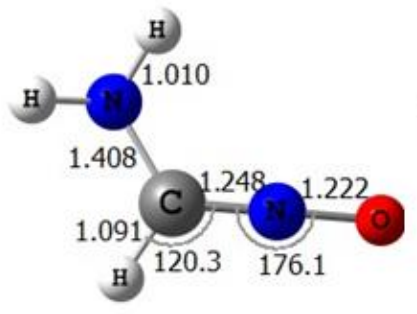

T1a1b $\left(C_{1}\right)$

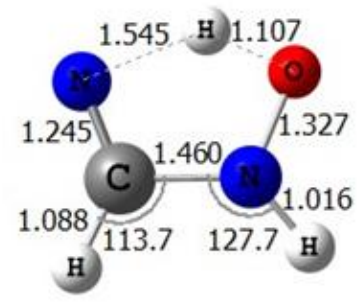

T11/10 $\left(C_{1}\right)$

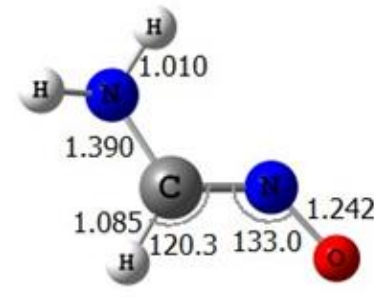

IS1b $\left(C_{1}\right)$

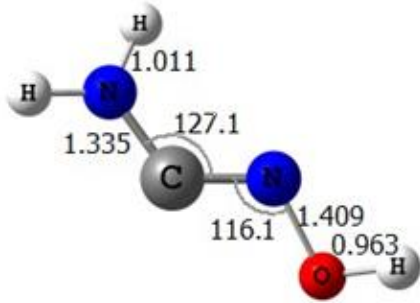

IS2 $\left(C_{1}\right)$

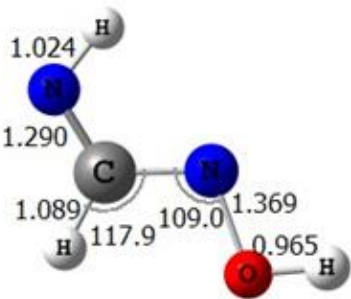

IS9 $\left(C_{1}\right)$

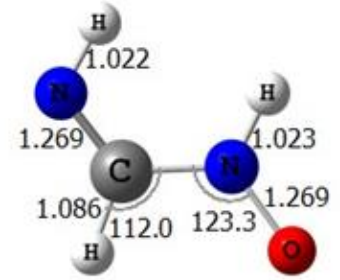

IS11 ( $\left.C_{1}\right)$

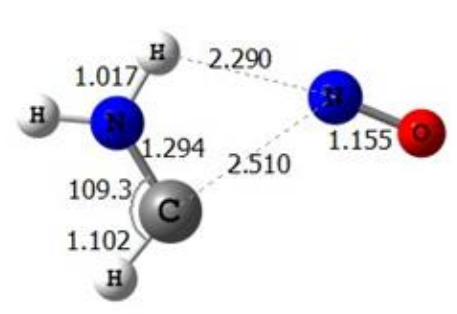

$\operatorname{COM}\left(\mathrm{C}_{1}\right)$

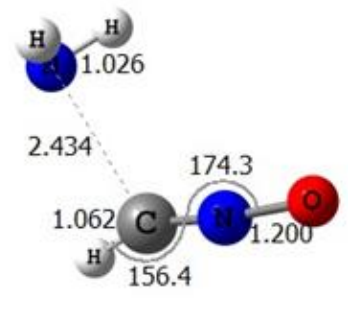

T0/1 ( $\left.\mathrm{C}_{1}\right)$

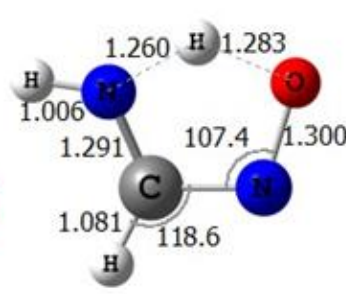

$\mathrm{T} 1 / 9\left(\mathrm{C}_{1}\right)$

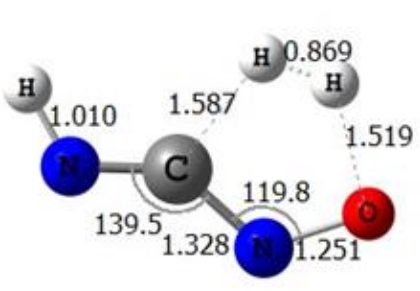

T9P3 $\left(C_{1}\right)$

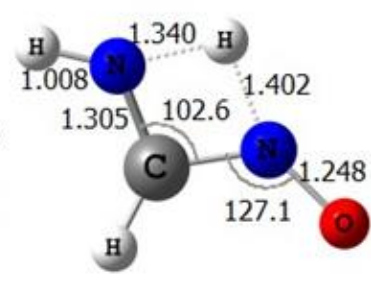

$\mathrm{T} 1 / 11\left(\mathrm{C}_{1}\right)$

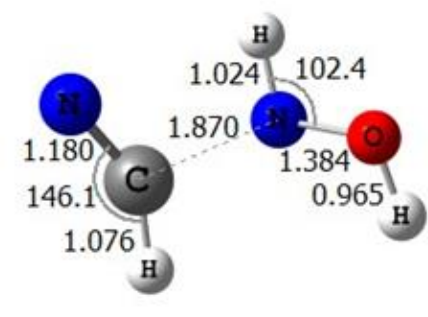

T10P13 $\left(C_{1}\right)$

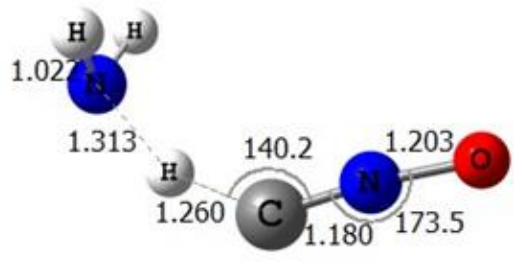

T0P1 (C 1 )
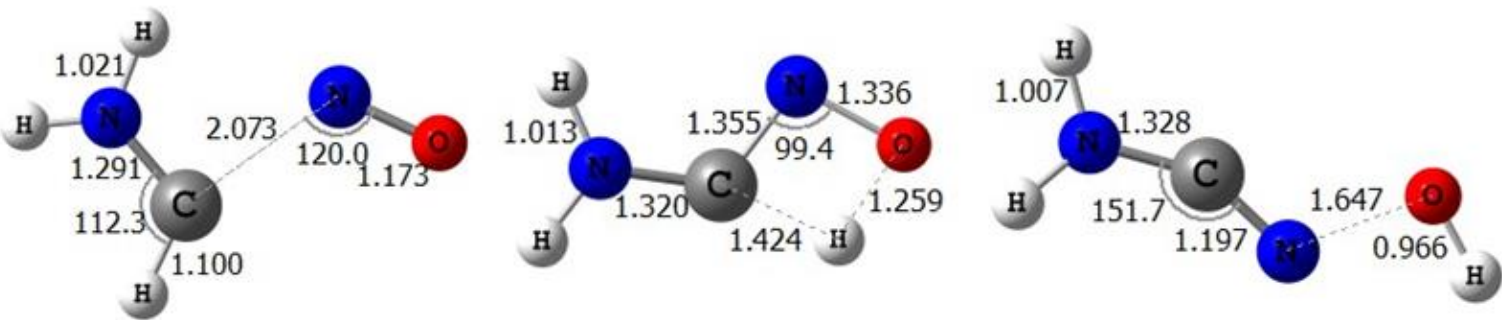

$\operatorname{T1P2}\left(C_{1}\right)$

T 1/2 (C 1 )

T2P6 ( $\left.\mathrm{C}_{1}\right)$

Figure 2: Geometries of main intermediates and transition states involved in the $\mathrm{HCNO}+\mathrm{NH}_{2}$ reaction, optimized at the B3LYP/6-311++G(3df,2p) level of theory (Bond lengths in $\AA$ and angles in degree). Molecular point groups are indicated in parentheses. 


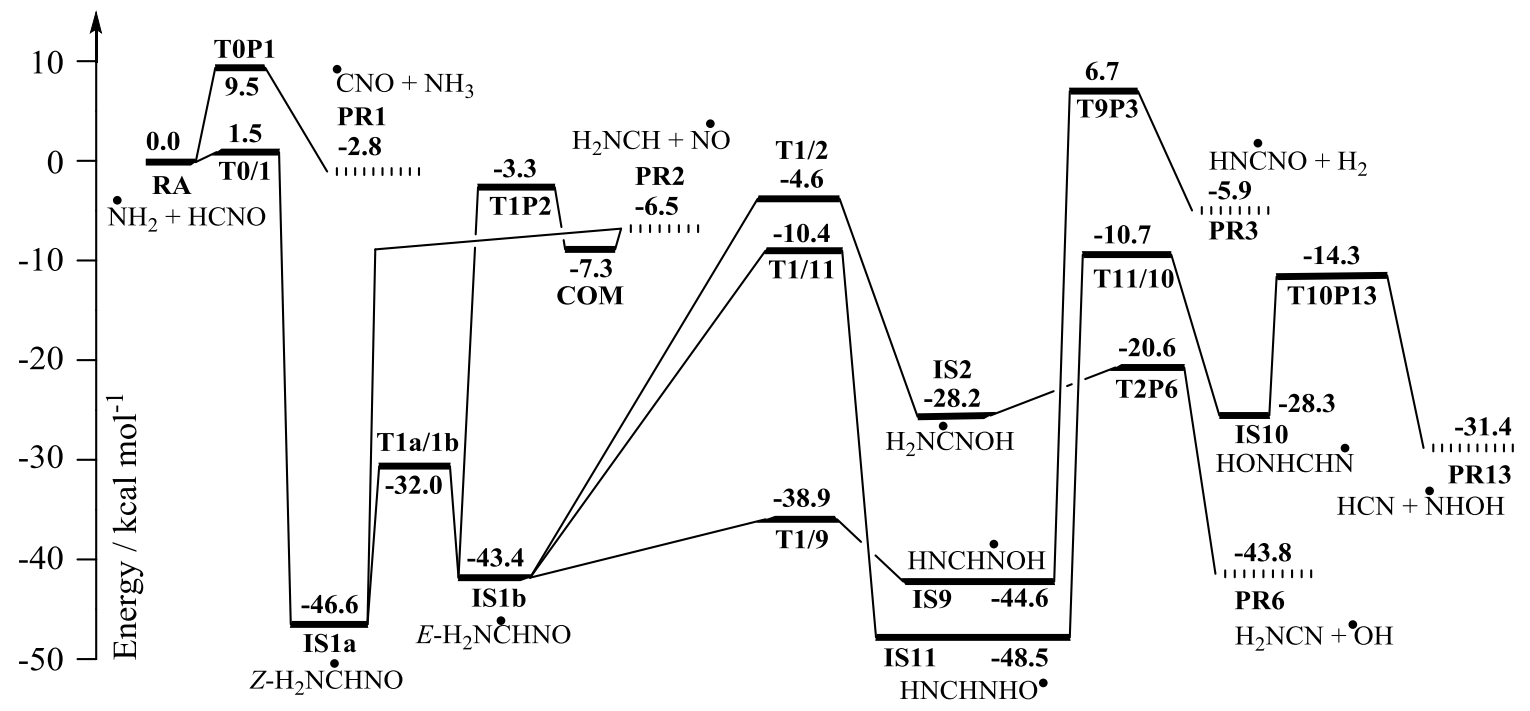

Figure 3: Kinetically most relevant section of the potential energy surface of the $\mathrm{HCNO}+\mathrm{NH}_{2}$ reaction, calculated at the CCSD(T)/CBS(DTQ)//B3LYP/6-311++G(3df,2p) + ZPVE level of theory. Only reactions related to five lowest product channels are shown; see supporting information for a complete PES comprising 17 intermediates, $46 \mathrm{TS}$, and 14 product fragments.

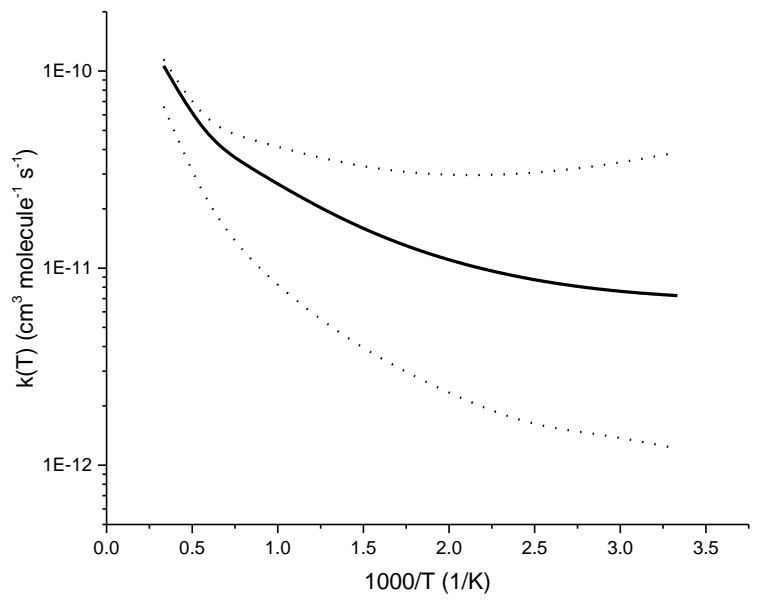

Figure 4: Overall rate coefficient $\mathrm{k}(\mathrm{T})$ for the reaction of $\mathrm{HCNO}+\mathrm{NH}_{2}$, averaged across pressures from $10^{-3}$ to $10^{3}$ bar. The area between the dotted lines indicates the uncertainty of the a priori prediction. 

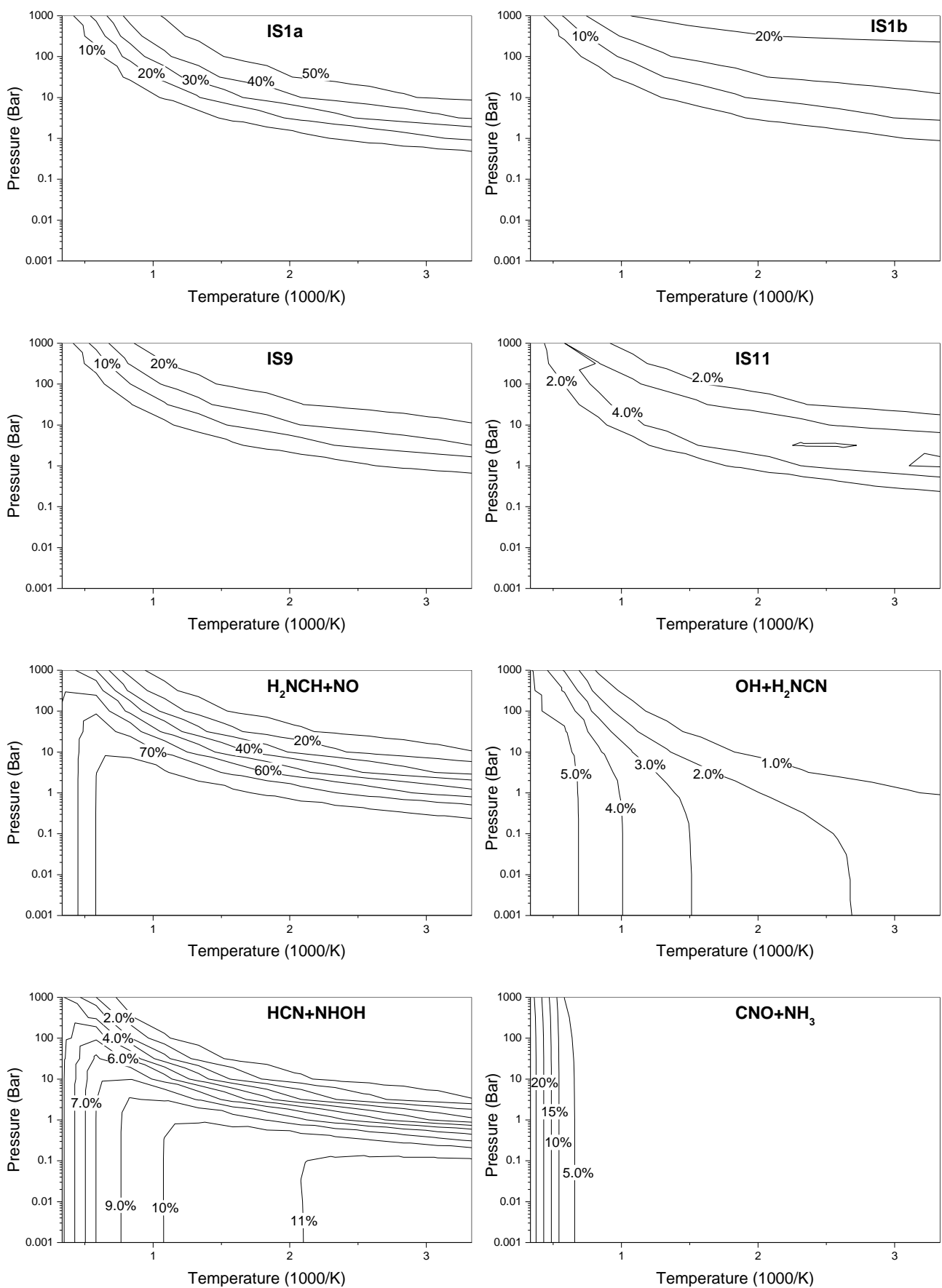

Figure 5: Temperature- and pressure-dependent product distributions for the $\mathrm{HCNO}+\mathrm{NH}_{2}$ reaction. The yield of all other products and adducts is negligible in in all reaction conditions. 

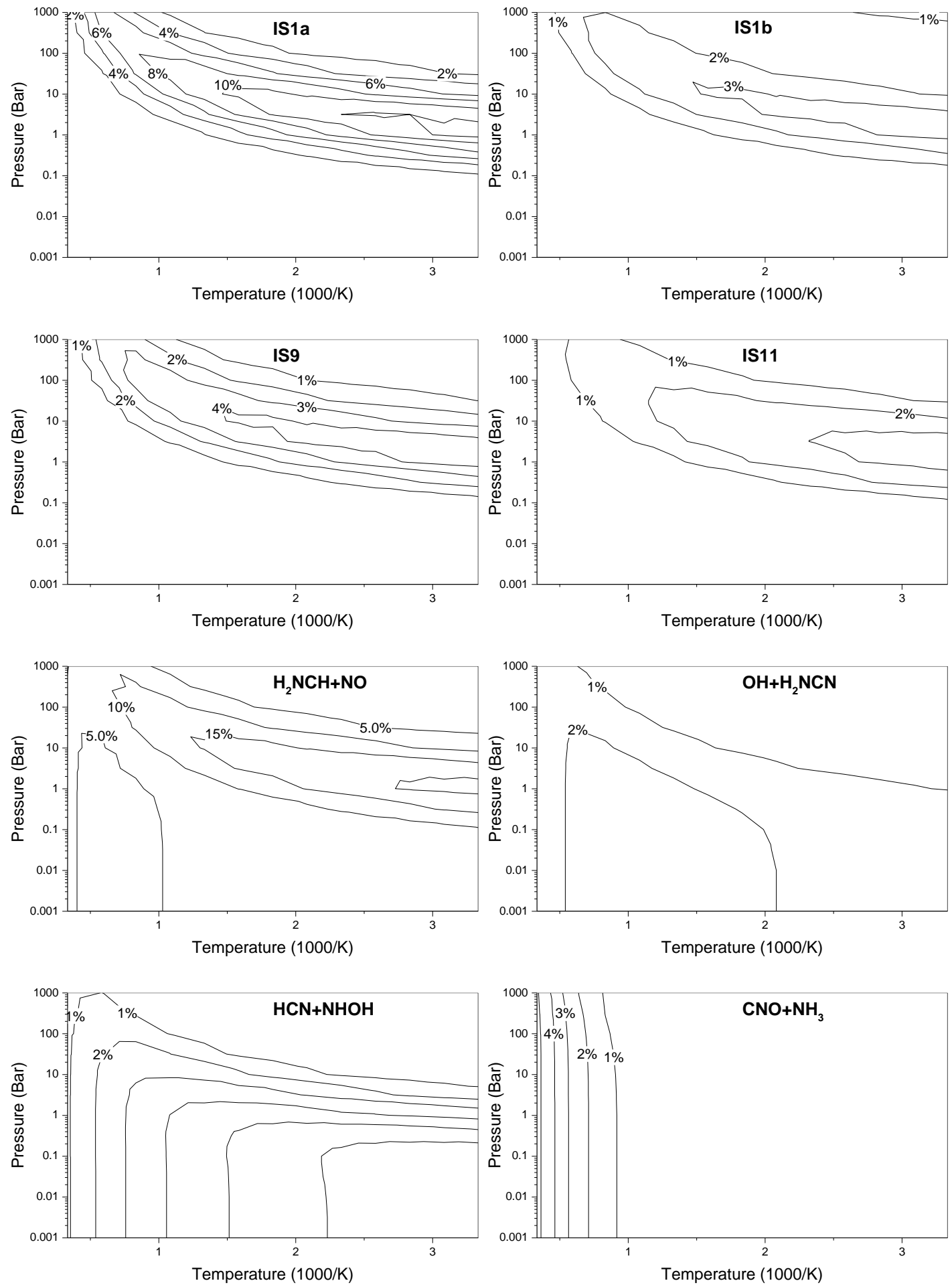

Figure 6: Symmetrized uncertainty, indicated in absolute $\%$, on the product distribution of the $\mathrm{HCNO}+\mathrm{NH}_{2}$ reaction, obtained from a brute-force error analysis varying the most sensitive parameters in the kinetic analysis. 
Table 1: Comparison of calculated heats of reaction $\left(\mathrm{kcal} \mathrm{mol}^{-1}\right)$ for the 14 identified products from the $\mathrm{CNO}+\mathrm{NH}_{2}$ reaction, against available literature data at $298.15 \mathrm{~K}$. Levels of theory used are B3LYP/6-311++G(3df,2p) (designated as B3LYP), CCSDT)/6-311++G(3df,2p) (CCSD(T)) and CCSD(T)/aug-Schwartz6(DTQ) (CCSD(T)/CBS).

\begin{tabular}{|c|c|c|c|c|}
\hline Species & B3LYP & $\operatorname{CCSD}(\mathrm{T})$ & $\mathrm{CCSD}(\mathrm{T}) / \mathrm{CBS}$ & $\begin{array}{l}\text { Literature } \\
\text { value [44] }\end{array}$ \\
\hline PR1 $\left(\mathrm{NH}_{3}+\mathrm{CNO}\right)$ & -2.2 & -2.9 & -2.8 & -2.5 \\
\hline PR2 $\left(\mathrm{NO}+\mathrm{H}_{2} \mathrm{NCH}\right)$ & -2.2 & -6.9 & -6.4 & --- \\
\hline PR3 $\left(\mathrm{H}_{2}+\mathrm{HNCNO}\right)$ & -11.9 & -6.5 & -5.9 & --- \\
\hline PR4 $\left(\mathrm{HCN}+\mathrm{NH}_{2} \mathrm{O}\right)$ & -36.1 & -38.2 & -38.6 & --- \\
\hline PR5 $\left(\mathrm{NCO}+\mathrm{NH}_{3}\right)$ & -64.3 & -65.3 & -65.3 & -65.4 \\
\hline PR6 $\left(\mathrm{NH}_{2} \mathrm{CN}+\mathrm{OH}\right)$ & -38.4 & -42.8 & -43.8 & --- \\
\hline PR7 (H + HNCNOH) & 10.2 & 8.0 & 7.8 & --- \\
\hline PR8 (H + HCN(H)NO_cy) & 50.7 & 42.5 & 43.0 & --- \\
\hline PR9 $\left(\mathrm{HNCN}+\mathrm{H}_{2} \mathrm{O}\right)$ & -63.5 & -64.9 & -66.3 & -65.7 \\
\hline PR10 $\left(\mathrm{H}_{2} \mathrm{O}+\mathrm{NC}(\mathrm{H}) \mathrm{N}\right)$ & -19.7 & -25.6 & -26.4 & --- \\
\hline PR11 $\left(\mathrm{NO}+\mathrm{H}_{2}+\mathrm{HCN}\right)$ & -25.2 & -33.5 & -31.7 & -31.4 \\
\hline PR12 $(\mathrm{H}+\mathrm{HON}(\mathrm{H}) \mathrm{CN})$ & 9.5 & 2.5 & 2.6 & --- \\
\hline PR13 (HNOH + HCN) & -26.5 & -30.9 & -31.4 & -31.4 \\
\hline PR14 $\left(\mathrm{CH}_{2} \mathrm{NH}+\mathrm{NO}\right)$ & -36.8 & -42.5 & -42.0 & --- \\
\hline
\end{tabular}


Table 2: Theoretical predictions of relative energies $\left(\mathrm{kcal} \mathrm{mol}^{-1}\right)$ for the most critical reactants, intermediates, transition states, and products of the $\mathrm{NH}_{2}+\mathrm{HCNO}$ reaction calculated at three levels of theory i.e. B3LYP/6-311++G(3df,2p) (designated as B3LYP), CCSDT)/6-311++G(3df,2p) (CCSD(T)) and $\operatorname{CCSD}(\mathrm{T}) /$ aug-Schwartz6(DTQ) (CCSD(T)/CBS), all based on optimized B3LYP geometries. See supporting information for an extended list covering the full PES.

\begin{tabular}{|c|c|c|c|c|}
\hline Species & & $\begin{array}{c}\Delta \mathrm{E}(\mathrm{kcal} / \mathrm{mol}) \\
\text { B3LYP }\end{array}$ & $\begin{array}{c}\Delta \mathrm{E}(\mathrm{kcal} / \mathrm{mol}) \\
\mathrm{CCSD}(\mathrm{T})\end{array}$ & $\begin{array}{c}\Delta \mathrm{E}(\mathrm{kcal} / \mathrm{mol}) \\
\mathrm{CCSD}(\mathrm{T}) / \mathrm{CBS}\end{array}$ \\
\hline RA & $\mathrm{HCNO}+\mathrm{NH}_{2}$ & 0.0 & 0.0 & 0.0 \\
\hline IS1a & $\mathrm{Z}-\mathrm{HC}\left(\mathrm{NH}_{2}\right) \mathrm{NO}$ & -46.0 & -44.9 & -46.6 \\
\hline IS1b & $E-\mathrm{HC}\left(\mathrm{NH}_{2}\right) \mathrm{NO}$ & -43.4 & -41.8 & -43.4 \\
\hline IS2 & $\mathrm{H}_{2} \mathrm{NCNOH}$ & -25.5 & -25.6 & -28.2 \\
\hline IS9 & HNCHNOH & -41.1 & -42.7 & -44.6 \\
\hline IS10 & NCHNHOH & -24.1 & -27.0 & -28.3 \\
\hline IS11 & HNCHNHO & -46.9 & -46.8 & -48.5 \\
\hline COM & $\mathrm{H}_{2} \mathrm{NCH}-\mathrm{NO}$ & -4.1 & -6.8 & -7.3 \\
\hline T0/1 & & 1.3 & 2.2 & 1.5 \\
\hline T1P2 & & -3.4 & -2.1 & -3.3 \\
\hline T1a1b & & -33.4 & -30.5 & -32.0 \\
\hline $\mathrm{T} 1 / 2$ & & -2.3 & -2.0 & -4.6 \\
\hline $\mathbf{T} 1 / 9$ & & -35.3 & -35.9 & -38.9 \\
\hline $\mathbf{T} 1 / 11$ & & -10.1 & -8.1 & -10.4 \\
\hline T11/10 & & -7.8 & -8.2 & -10.7 \\
\hline T0P1 & & 5.4 & 10.4 & 9.5 \\
\hline T2P6 & & -19.9 & -18.1 & -20.6 \\
\hline T9P3 & & 3.9 & 8.5 & 6.7 \\
\hline T10P13 & & -11.1 & -12.7 & -14.3 \\
\hline PR1 & $\mathrm{NH}_{3}+\mathrm{CNO}$ & -1.9 & -2.7 & -2.8 \\
\hline PR2 & $\mathrm{NO}+\mathrm{H}_{2} \mathrm{NCH}$ & -1.5 & -6.2 & -6.5 \\
\hline PR3 & $\mathrm{H}_{2}+\mathrm{HNCNO}$ & -12.3 & -6.8 & -5.9 \\
\hline PR6 & $\mathrm{NH}_{2} \mathrm{CN}+\mathrm{OH}$ & -38.0 & -42.5 & -43.8 \\
\hline PR13 & $\mathrm{HNOH}+\mathrm{HCN}$ & -25.8 & -30.3 & -31.4 \\
\hline
\end{tabular}

